\title{
Cobs Porous Carbon-Based Materials With High Energy And Excellent Cycle Stability For Supercapacitor Applications
}

Moses Kigozi ( $\square$ mkigozi@aust.edu.ng )

Busitema University https://orcid.org/0000-0002-6463-9052

Richard K Koech

African University of Science and Technology

Kingsley Orisekeh

African University of Science and Technology

Ravi Kali

ARCl: International Advanced Research Centre for Powder Metallurgy and New Materials

Omar L M Kamoga

Busitema University

\section{Balaji Padya}

ARCl: International Advanced Research Centre for Powder Metallurgy and New Materials

Abdulhakeem Bello

African University of Science and Technology

Gabriel N Kasozi

Makerere University

\section{Pawan Kumar Jain}

ARCl: International Advanced Research Centre for Powder Metallurgy and New Materials

John Baptist Kirabira

Makerere University

Azikiwe Peter Onwualu

African University of Science and Technology

Nelson Y Dzade

Cardiff University

Original article

Keywords: Excellent stability, High capacitance, Porous carbon, Supercapacitor application, maize cobs

Posted Date: September 24th, 2021

DOI: https://doi.org/10.21203/rs.3.rs-889321/v1 
License: (c) (i) This work is licensed under a Creative Commons Attribution 4.0 International License. Read Full License 


\section{Abstract}

Background and purpose: For application in supercapacitors, improving the efficiency of the electrode materials is the most important for obtaining high performance. Porous carbon with suitable architectures is reliable for improved electrochemical capacitors. In this study, we optimized the maize cobs as a potential abundant precursor for the production of porous carbon supercapacitor applications. This research study aimed to advance on the activation method for Activation of the biomass and to upcycling agricultural biomass into carbon-based porous materials for supercapacitor electrode application. The carbonized samples were kept in a desiccator for 3 hours to allow intercalation and interaction of the carbon lattice expansion by $\mathrm{K}^{+}$ion before Activation [Topic, RQ].

Results: The physical and chemical characterization of the synthesized materials was carried out several techniques for determining different properties of the activated carbon from maize cobs, including; structural-functional groups, morphology, chemical composition, physical properties and electrochemical performance. The results revealed surface structure with oxygen-based functional groups carried by XPS and FTIR, the amorphous nature by XRD, high-temperature stability to degradation by TGA/DSC, among others. Also, the structural characterization revealed a BET specific surface area of $1443.94 \mathrm{~m}^{2} / \mathrm{g}$ with a pore volume of $0.7915 \mathrm{~cm}^{3} / \mathrm{g}$. Symmetric devices based on the produced materials delivered a specific capacitance of $358.7 \mathrm{~F} / \mathrm{g}$ with an energy density of $12.45 \mathrm{Wh} / \mathrm{kg}$ and a corresponding power density of $250 \mathrm{~W} / \mathrm{kg}$ at $0.5 \mathrm{~A} / \mathrm{g}$ [Outcome].

Conclusions: The as-prepared electrodes exhibited excellent stability with the capacitance retention of $99 \%$ at the maximum potential for a repeated $10 \mathrm{hr}$ to a total of $130 \mathrm{~h}$. The industries can commercialise these activated carbon materials for application in energy storage systems and water purification due to their porosity and high-temperature resistance to degradation [Contributions].

\section{Background}

Technology evaluation globally has shown that there is a massive demand for energy consumption. This is due to the increasing population and the number of gadgets which are developed to simplify life. In generation Alpha, the interaction with artificial intelligence and automated voice becomes an integral part of standard systems and impacts health, life, and future generation. All these aspects require power to be renewable and sustainable. Renewable energy harvested from sources like solar/ hydro, wind, and geothermal is not produced continuously because it is time and weather-dependent. Energy storage accumulators such as supercapacitors and batteries are required [2, 3]. Supercapacitors (SCs) have attracted tremendous attention in today's energy storage research due to their excellent performance of high power density, high cycling stability, and quick charge/discharge process [2-5].

Supercapacitors are categorized depending on their mechanism of energy storage which includes; (i) electrical chemical double-layer capacitor (EDLC), which store their energy by accumulation of charges in a Helmholtz double-layer interaction between electrolyte and electrode, (ii) pseudocapacitors with storage 
achieved by a reversible faradic redox reaction between electrolyte and electrodes [2-4, 6], (iii) hybrid supercapacitors formation by coupling of different redox and EDLC materials [7]. The EDLC electrode materials (activated carbon (AC)) have unique properties, including high volume/low density and large specific surface area, which improves optimized porosity, wettability, high electrolytic ion adsorption, and excellent electrical conductivity[4]. Activated carbon (AC) is widely used as electrode material for supercapacitors and obtained from the Activation of biomass. This is because biomass is economically viable and abundant in nature $[4,5,8]$. The $A C$ materials are recently derived mainly from renewable and sustainable resources such as agricultural crop wastes, biomass, and domestic waste, which are ecofriendly and renewable $[1,8]$.

There are generally two main activation processes, including physical and chemical Activation, used to synthesize AC from biomass. Chemical Activation is used commonly because of its low activation time, low temperatures, uniform pore size distribution, high yield, and controllable specific surface area compared to the physical process [1]. The chemical activation commonly employs activation agents include potassium hydroxide $(\mathrm{KOH})$, sulphuric acid $\left(\mathrm{H}_{2} \mathrm{SO}_{4}\right)$, sodium hydroxide $(\mathrm{NaOH})$, phosphorous acid $\left(\mathrm{H}_{3} \mathrm{PO}_{4}\right)$, zinc chloride $\left(\mathrm{ZnCl}_{2}\right)$, among others which are applied extensively at different temperatures and different atmospheres $[6,8]$. Several articles on EDLC supercapacitors have reported different AC from biomass. Other materials, which include African maize corn cob with SSA of $254 \mathrm{~m}^{2} / \mathrm{g}$ and a specific capacitance of $456 \mathrm{~F} / \mathrm{g}$ at a specific current of $0.25 \mathrm{~A} / \mathrm{g}$ [1], waste tea with SSA of $294.6 \mathrm{~m}^{2} / \mathrm{g}$ exhibited a specific capacitance of $199 \mathrm{~F} / \mathrm{g}$ at the specific current of $0.5 \mathrm{~A} / \mathrm{g}$, the SSA range of $1308 \mathrm{~m}^{2} / \mathrm{g}$ gave a specific capacitance of $140 \mathrm{~F} / \mathrm{g}$ at a current density of $0.1 \mathrm{~A} / \mathrm{g}$ from Waste tea [9]. Rosewood and corn cob [10], banana peels [11], corn husk with SSA of $1370 \mathrm{~m}^{2} / \mathrm{g}$, and a specific capacitance of $127 \mathrm{~F} / \mathrm{g}$ at $1 \mathrm{~A} / \mathrm{g}$ [8] were reported. Pinecones with SSA of $1169.31 \mathrm{~m}^{2} / \mathrm{g}$ show a specific capacitance of $43 \mathrm{~F} / \mathrm{g}$ at $0.5 \mathrm{~A} / \mathrm{g}$ [4], coconut shell exhibited SSA of $11614 \mathrm{~m}^{2} / \mathrm{g}$ resulted in a high capacitance of $426 \mathrm{~F} / \mathrm{g}$ at $0.5 \mathrm{~A} / \mathrm{g}$ with electronic conductivity of $11.43 \mathrm{~S} / \mathrm{cm}$ [12]. Tongcao biomass was reported to have an SSA of 1425.2 $\mathrm{m}^{2} / \mathrm{g}$ with a gravimetric capacitance of $244.51 \mathrm{~F} / \mathrm{g}$ at a scan rate of $20 \mathrm{mV} / \mathrm{s}$ [5]. Lastly, nitrogen-doped porous carbon (NPC)/mesophase pitch exhibited an SSA of $503.8 \mathrm{~m}^{2} / \mathrm{g}$ with a specific capacitance of 232.2 $\mathrm{F} / \mathrm{g}$ at $2 \mathrm{~A} / \mathrm{g}[13]$.

Generally, in EDLC, the charge is stored at the interface of the electrolyte/electrode system. This is controlled primarily by a high specific surface area (SSA) with the appropriate distribution of the pore volume (micropores, mesopores, and macropores) of the materials for the electrode to improve the electrochemical performance. When activating biomass for carbon-derived material for supercapacitor, the process needs to be optimized for improvement for high SSA and adequate distribution of the pore volume, which can enhance the electrochemical storage performance. It has been shown that a high SSA with the proper distribution of mesopores and micropores is an important parameter that is necessary to obtain a better performance of porous EDLCs carbon electrodes. Still, a definite relationship between the capacitance and SSA has not been clearly shown $[14,15]$. Using porous carbon is favourable because the pore structure governs the measured capacitance, energy storage, and power delivery capability of the material. These result from contribution due to the total surface of micropores and the surface of larger 
pores (mesopores and macropores) [14]. It is worth stating that the macropores (> $50 \mathrm{~nm}$ ) make virtually no contribution to the total capacitance. Still, it acts as the ion buffering reservoir [16]. In comparison, micropores ( $<2 \mathrm{~nm}$ in size) serve as the ion traps for energy storage, and mesopores $(2<50 \mathrm{~nm})$ act as the ion transport pathways for power delivery $[16,17]$. In order to achieve the required porosity and morphology of the materials, different activation agents are employed, as mentioned earlier. Still, so the optimization of carbonization and activation temperature is necessary. This research work aimed to optimize the temperature for Activation of Zea mays cob to improve porosity, morphology, and performance. The activating agent in this study was $\mathrm{KOH}$, the most frequently used for the different biomass activation processes. $\mathrm{KOH}$ gives better porosity and large SSA because of its comprehensive cation, the carbon lattice expansion by $\mathrm{K}^{+}$ion intercalation, its synergistic, and their chemical activation [4, 18]. The $\mathrm{KOH}$ activation proved to give excellent electrode materials that contribute to pseudocapacitance with heteroatoms bonded on the material's surface [19]. Previously, we reported an acid treatment of maize cobs that lead to an SSA of $357 \mathrm{~m}^{2} / \mathrm{g}$ with good electrochemical performance [1]. In this current work, the maize cobs derived porous activated carbon materials were carbonization at $400{ }^{\circ} \mathrm{C}$ for $90 \mathrm{~min}$ and $\mathrm{KOH}$ activation at different temperatures $\left(600,700\right.$, and $\left.800^{\circ} \mathrm{C}\right)$ using a ratio of $1: 4$ of the sample with $\mathrm{KOH}$. The composition of the samples and activation agents held for 3 hours before Activation to allow the carbon lattice expansion by $\mathrm{K}^{+}$ion intercalation. The produced carbon materials were used to fabricate symmetric devices and tested in two and three-electrode configurations to evaluate the electrochemical performance.

\section{Results And Discussion}

\section{Morphology and structural characterization}

The morphology of the three activated carbon materials was analyzed by FESEM/EDS, as stated earlier, and the results are shown in Fig. 1. The AC samples exhibited irregular sheets with apparent porosities. This implies that the morphology could be from the volatile organics and swell expansion, as Xie et al. [10] and Wang et al [5] reported. The three-carbon samples exhibited rough surfaces with excellent porosity creating a perfect interface for diffusion and intercalation of the electrolytic ions during the charge-discharge process of the EDLC electrodes. The visible surface porous structure of the samples varied with the varying temperature. ANN6 (Fig. 1a) exhibited huge irregular pores similar to a honeycomb structure comparable to ANN7, as shown in Fig. 1b. However, the ANN8 (Fig. 1c) indicates a densely packed structure than the ANN6 and ANN7, which we refer to as better in-depth porosity.

The EDS (Energy dispersive spectroscopy) and the elemental mapping of all three (3) samples confirm the presence of carbon materials with $75-99 \%$ wt in the Activation with $\mathrm{KOH}$. This creates high porosity with a high surface area due to redox reactions and the evolution of volatile organics as gases, increasing the porosity [20]. The EDS of ANN6 shown $99.48 \%$ carbon with some silica and sulphur as other elements. The ANN7 exhibited $89.47 \%$ carbon with silica and calcium as the other elements. ANN8 sample exhibited $75.22 \%$ carbon, as shown in Table 1 and the spectra in Fig. 1. with increasing temperature, the grains 
agglomerate and grow, the number of the open pores reduces, and the open pores locate at multi-grain boundaries. This degrades the carbonous materials as it further loses the lower weight carbon molecules at higher temperatures and creates increase in the ash contents which may be detected as silica content. The higher value of silica in ANN8 is due to increased activation temperature, leading to the formation of silica groups. The silica functional groups also improve the wettability between the electrode carbon surface and electrolytic ions by forming polar functional groups. When the surface has more functional groups concentrations, it increases the interaction between activated carbon surfaces and water in the electrolyte.

Table 1

EDS elemental composition for ANN6, ANN7, and ANN8 AC samples

\begin{tabular}{|lllll|}
\hline Sample & C & Si & S & Ca \\
\hline ANN6 & 99.48 & 0.48 & 0.04 & - \\
\hline ANN7 & 89.47 & 7.91 & - & 2.62 \\
ANN8 & 75.22 & 18.43 & - & 6.35 \\
\hline
\end{tabular}

The study carried out XRD analysis of the activated carbon was to confirm the phase composition, as shown in Fig. 2a. The spectra exhibited typical firm, broad peaks at $2 \theta=23.3^{\circ}$ and $43.1^{\circ}$, corresponding to (002) and (100) lattice planes for all the samples, respectively [12, 21-23]. The peak formation at $2 \theta=$ $23.2^{\circ}$ with planes of (002) indicates a graphitic structure and amorphous morphological phase in the derived activated carbon materials [24]. The degree of graphitization is closely related to the conductivity of the carbon materials [25]. The JCPDS card no. 41-1487 show the profile of ANN6 and ANN7 at $2 \theta=23$ and $40-43^{\circ}$ with a d-spacing of $4.435-4.456 \AA$ and $2.214-2.228 \AA$, respectively. The shift in the $2 \theta$ value of ANN8 towards large angles at high-temperature sample leads to the change in the d-spacing at $2 \theta=$ $26.4^{\circ}$ and $43.09^{\circ}$ to $3.380 \AA$ and $2.108 \AA$, respectively. This is also visible in their morphology, where ANN8 is different from the other two. In all three samples, the $d$-spacing at $2 \theta=23^{\circ}$ is greater than $3.35 \AA$ (for graphite), indicating hard carbon formation [1]. The decrease in d-spacing was causing a reduction in non-crystallinity, as shown in Fig. 1 between ANN6, ANN7, and ANN8 morphology variation [8].

The FTIR spectra of derived activated carbon are shown in Fig. 2b. The fingerprint region (1500-600) indicated three prominent firm peaks of $\mathrm{C}-\mathrm{OH}, \mathrm{C}-\mathrm{O}-\mathrm{C}, \mathrm{C}-\mathrm{H}, \mathrm{C}-\mathrm{N}$, and $\mathrm{C}-\mathrm{O}$ for the skeleton of the materials. Also, the diagnostic region (4000-1500 $\mathrm{cm}^{-1}$ ) exhibited the primary vibration at $1737 \mathrm{~cm}^{-1}$ for the three samples as the most substantial peak. This can be attributed to the frequency vibration of the $\mathrm{C}=0$ stretching in the structure of lactone, carboxyl, or quinone groups stretching in aromatic which are more intense in the activated carbon. Other characteristic peaks present include $\mathrm{sp}^{3}(\mathrm{C}-\mathrm{H}), \mathrm{sp}^{2}(\mathrm{C}-\mathrm{H})$ stretching vibration (2990 to $\left.3050 \mathrm{~cm}^{-1}\right)$, and $0-\mathrm{H} / \mathrm{sp}$ stretching vibration $\left(3450 \mathrm{~cm}^{-1}\right)$. The vibration stretching between $2990-3050 \mathrm{~cm}^{-1}$ is attributed to the $\mathrm{C}-\mathrm{H}$ stretch and out of plane bending vibration. The fingerprint region exhibited bending vibration of $\mathrm{C}-\mathrm{H}$ or $\mathrm{C}-\mathrm{N}$, which indicates the reaction of 
dehydrogenation. This is accelerated with the increase in temperature of Activation. The functional groups' information and frequency vibrations are consistent with the literature $[3,13,26]$.

The composition and functional groups of the samples were further examined by the XPS technique as shown in Fig. 3 and Figure S1 (supplementary information) with their binding energy and assignment of C1s, 01s, and Si2p. The samples exhibited no significant difference in their positions and shapes for different temperature treatments. The deconvolution of the C1s for sample ANN8 in Fig. 3, ANN7 and ANN6 spectra Fig. 1S (Supplementary information) was observed in five-carbon states as follows; C-C and $\mathrm{sp}^{2}$ at $284 \mathrm{eV}, \mathrm{C}-\mathrm{O}, \mathrm{C}-\mathrm{N}$ at $285.5 \mathrm{eV}, \mathrm{C}-\mathrm{C}$ at $287.8 \mathrm{eV}, \mathrm{O}-\mathrm{C}=\mathrm{O}, \mathrm{C}=\mathrm{O}$ at $289 \mathrm{eV}$. The Si2p exhibited one peak at $102 \mathrm{eV}$, which indicates Si-O and the 01s shown two oxygen states of $\mathrm{C}=\mathrm{O}$ at $532 \mathrm{eV}$ and $\mathrm{C}-\mathrm{O}$ at $534 \mathrm{eV}$. The spectra states are consistent with the other literature as reported $[4,11,27,28]$. The denoted functional groups of $\mathrm{O}=\mathrm{C}, \mathrm{C}-\mathrm{O}-\mathrm{H}, \mathrm{C}-\mathrm{O}-\mathrm{C}$, among others, are typical structures of phenolic, ester, quinine, lactonic, carboxyl group from the surface of the materials. Table 2 shows the atomic percentages from XPS analyses. This depicted a considerable decrease in carbon and oxygen percentage, attributed to an increase in temperature that caused an increase in the silica percentage at a higher temperature of Activation $[9,29]$.

Table 2

Atomic percentages as obtained from

XPS analysis

\begin{tabular}{|llll|}
\hline Sample & \multicolumn{3}{l}{ Atomic concentration (\%) } \\
\cline { 2 - 4 } & C 1s & 0 1s & Si 2p \\
\hline ANN8 & 51.86 & 37.68 & 10.46 \\
\hline ANN7 & 75.66 & 24.08 & 5.26 \\
\hline ANN6 & 83.46 & 14.48 & 2.05 \\
\hline
\end{tabular}

The thermogravimetric analysis (TGA/DSC) was carried out to confirm the degradation and purity of the ANN6, ANN7, and ANN8 samples materials. The study collected TGA/DSC data by heating the three samples to $1000^{\circ} \mathrm{C}$ under a pure airflow as shown in Fig. 4a and the TGA data in Table 3 .

Table 3

TGA/DSC material decomposition of the raw material and activated carbon samples

\begin{tabular}{|lllll|}
\hline \multirow{2}{*}{ Decomposition stages } & \multicolumn{4}{l}{ Mass fraction (\%) lost at different stages } \\
\cline { 2 - 5 } & Raw material & ANN6 & ANN7 & ANN8 \\
\hline I & 10.4 & 2.1 & 2.5 & 2.5 \\
\hline II & 63 & 10.9 & 23.7 & 26.1 \\
\hline III & & 16.4 & - & - \\
\hline At $1000^{\circ} \mathrm{C}$ & 15.3 & 67.1 & 49.3 & 43.8 \\
\hline
\end{tabular}

Page $7 / 27$ 
The TGA data collected on the raw material Zea mays cobs shown in Fig. 4a exhibited two distinct decomposition stages; the $1 \mathrm{st}$ stage is at 210 to $260^{\circ} \mathrm{C}$, and the $2 \mathrm{nd}$ stage is between 350 to $370^{\circ} \mathrm{C}$. The heat flow through the raw material exhibited exothermal and endothermal flow. The first endothermic phase at $100^{\circ} \mathrm{C}$ was due to moisture in the sample. The second endothermic demonstrated loss of water of crystallization at $360^{\circ} \mathrm{C}$, after which the heat flow was uniform throughout up to $1000^{\circ} \mathrm{C}$, with the highest exothermal phase at $352{ }^{\circ} \mathrm{C}$ with $0.70 \mathrm{~mW} / \mathrm{mg}$. The material decomposition was up to $85 \%$ mass loss at $1000^{\circ} \mathrm{C}$. ANN6 sample material (Fig. 4b) exhibited three decomposition stages; the 1st and 2nd between 45 to $114^{\circ} \mathrm{C}$, the third stage at 286 to $298^{\circ} \mathrm{C}$ and the mass loss as shown in Table 3 . The heat flow through ANN6 exhibited endothermic and exothermic flow (Fig. 4b). The ANN7 and ANN8 sample materials exhibited two distinct similar decomposition stages. These are consistent with that of ANN6 for the first and second stages. Stage one and stage two decomposition may be due to organic volatile materials and moisture trapped after activation processes. The heat flow through the three materials exhibited the same trend with endothermic at $106^{\circ} \mathrm{C}$ and peak exothermic at around $351^{\circ} \mathrm{C}$ and 0.91 $\mathrm{mW} / \mathrm{mg}$.

Table 4

The pore characteristics of ANN6, ANN7, and ANN8 activated carbon samples

\begin{tabular}{|lllllllll|}
\hline Sample & $\begin{array}{l}\text { SBET } \\
\left(\mathbf{m}^{2} / \mathbf{g}\right)\end{array}$ & $\begin{array}{l}\mathrm{S}_{\text {mic }} \\
\left(\mathbf{m}^{2} / \mathbf{g}\right)\end{array}$ & $\begin{array}{l}\mathrm{S}_{\text {mic }} / \text { SBET } \\
(\mathbf{\%})\end{array}$ & $\begin{array}{l}\text { Sext } \\
\left(\mathbf{m}^{2} / \mathbf{g}\right)\end{array}$ & $\begin{array}{l}\mathrm{V}_{\text {micro }} \\
\left(\mathbf{c m}^{3} / \mathbf{g}\right)\end{array}$ & $\begin{array}{l}\mathrm{V}_{\text {meso }} \\
\left(\mathbf{c m}^{3} / \mathbf{g}\right)\end{array}$ & $\begin{array}{l}\mathrm{V}_{\text {total }} \\
\left(\mathbf{c m}^{3} / \mathbf{g}\right)\end{array}$ & $\begin{array}{l}\mathrm{V}_{\text {mic }} / \mathrm{V}_{\text {tot }} \\
(\%)\end{array}$ \\
\hline ANN6 & 461.36 & 385.66 & 83.6 & 75.71 & 0.1889 & 0.05749 & 0.2464 & 76.7 \\
\hline ANN7 & 972.65 & 689.28 & 70.87 & 460.76 & 0.3628 & 0.1682 & 0.5310 & 68.3 \\
\hline ANN8 & 1443.94 & 1000.89 & 69.30 & 383.05 & 0.5167 & 0.27485 & 0.7915 & 65.3 \\
\hline
\end{tabular}

The BET technique determined the porosity and the specific surface area (SSA) as shown in Fig. 5 of the Zea mays derived activated carbon. The $\mathrm{N}_{2}$ adsorption-desorption isotherm was performed to calculate the pore volume and specific surface area, as shown in Table 4 for the three samples. The isotherms of the samples show type I isotherm with micropores, and the hysteresis loop is mainly caused by the mesoporous structure [10]. The hysteresis loop at a relative pressure from 0.4 to $0.9 \mathrm{P} / \mathrm{Po}$ in the adsorption-desorption isotherms mainly because of the presence of mesopores with the formation of interparticle condensation of $\mathrm{N}_{2}$ at $>0.9 \mathrm{P} / \mathrm{Po}$. The calculated SSA for ANN8 exhibited the highest value of $1443.94 \mathrm{~m}^{2} / \mathrm{g}$ with a total pore volume of $0.7915 \mathrm{~cm}^{3} / \mathrm{g}$. The samples ANN7 and ANN6 exhibited the SSA of 972.65 and $461.36 \mathrm{~m}^{2} / \mathrm{g}$ with a total pore volume of 0.5310 and $0.2464 \mathrm{~cm}^{3} / \mathrm{g}$, respectively, as shown in Table 4. Figure $5 \mathrm{~b}$ exhibited a pore size distribution of the three samples with an average mean pore diameter of $6.39,7.71$, and $7.91 \mathrm{~nm}$ for ANN6, ANN7, and ANN8, respectively [13]. The high surface area and averagely smaller pores are suitable for electrode materials for energy storage systems as its morphology can induce fast charge transfer which also contributes to an EDLC formation of surface interfaces for the electrode surfaces and electrolyte ions $[4,5,13]$. The specific surface area of ANN8 is higher than $1050 \mathrm{~m}^{3} / \mathrm{g}$ that was reported by Moses et al [1] which was performed without holding for 3 hours to allow intercalation of the carbon lattice expansion by $\mathrm{K}+$ ion before Activation. 


\section{Electrochemical characterization of materials}

The performance of as-prepared electrode materials was first tested in the three-electrode system using 6 $\mathrm{M} \mathrm{KOH}$ as the electrolyte. The CV curves for ANN6, ANN7, and ANN8 at a scan rate of $10 \mathrm{mV} / \mathrm{s}$ is shown in Fig. 6a. Sample ANN7 exhibited a slight discharge hump near $0.8 \mathrm{~V}$ due to some redox pseudocapacitance of the functional groups. All the CV curves exhibited a quasi-rectangular-like shape throughout the scanning range showing the excellent performance of EDLC $[25,30]$. The GCD curves for all the materials, as shown in Fig. 6b, indicated an isosceles triangular shape for the GCD profile carried at $0.25 \mathrm{~A} / \mathrm{g}$. This confirmed the dominant EDLC behaviour for the electrode material. The specific capacitance was determined using the discharge time at different current densities and equation one for the three samples, as shown in Fig. 6c. The highest specific capacitance of ANN6, ANN7, and ANN8 are $537.3 \mathrm{~F} / \mathrm{g}$ at $0.5 \mathrm{~A} / \mathrm{g}, 517.5 \mathrm{~F} / \mathrm{g}$ at $0.5 \mathrm{~A} / \mathrm{g}$, and $389.7 \mathrm{~F} / \mathrm{g}$ at $0.25 \mathrm{~A} / \mathrm{g}$, respectively. The other $\mathrm{GCD}$ plot for the samples exhibited the same $\mathrm{V}$-shape at different current density as shown in Figure $\mathrm{S} 2$ (Supplementary Information).

The samples exhibited an excellent specific surface area that matches performance. The performance is also influenced by the possible interaction of electrolyte ions and suitable porous surfaces of the materials and the heteroatomic function groups on the surface wettability. The sheet-like structure of the materials, as shown in Fig. 1, exposes the active sites for complete interface interaction for electrode surfaces and electrolyte ions. The results are comparable with the results reported in the literature $[13$, 31-33].

To objectively evaluate the electrochemical (EC) properties of the synthesized materials, including specific capacitance, energy density, power density, and stability, were determined. The study evaluated asprepared materials with the two-electrode configuration system. The CV was carried out at different scanning rates from $5 \mathrm{mV} / \mathrm{s}$ to $200 \mathrm{mV} / \mathrm{s}$ with a potential range from 0 to $1.0 \mathrm{~V}$ exhibiting quasirectangular shapes, as shown in Fig. 7. The GCD of the materials was evaluated at different current densities from 0.25 to $2.5 \mathrm{~A} / \mathrm{g}$ depicting V-shapes, as shown in Fig. 8. The CV and GCD curves estimated in the two-electrode system show no significant changes in shapes compared to those for the threeelectrode system, as shown in Fig. 6(a \& b). The CV for the as-prepared electrode materials in Fig. 7 all show similar quasi-rectangular shapes. The ANN6 (Fig. 7a) exhibited a redox reaction at the lower and upper potentials. This behaviour was also depicted in the ANN7 sample (Fig. 7b) but with fewer redox peaks. This may be due to the reversible redox reaction between the functional groups mainly originating from quinone or carbonyl (R) functional groups with the electrolyte, as illustrated in equation five created by the high concentration of oxygen functional group that tends to decompose at a sintered temperature of $750^{\circ} \mathrm{C}$ as shown in Fig. 4b.

$\mathrm{R}-\mathrm{C}_{\mathrm{X}}-\mathrm{O}+\mathrm{H}^{+}+\mathrm{e}^{-} \leftrightarrow \mathrm{R}-\mathrm{C}_{\mathrm{X}}-\mathrm{OH}(5)$

The ANN8 sample exhibited quasi-rectangular shapes without causing the Faradaic process. This may be attributed to the uniform porosity in the ANN8 sample, as shown in Fig. 1(ANN8), which is different from others. All the sample materials showed identical shapes at even higher rates of $200 \mathrm{mV} / \mathrm{s}$ without 
distorting the shapes by indicating the high stability of the materials. This also implies that the materials have excellent charge-discharge character [24,34]. The exhibited symmetrical rectangular shapes showed better performance than most reported results in the literature $[11,25,30,31]$. The CVs after stability demonstrated less or no exponential for the faradaic process, indicating no pseudocapacitance after holding the electrode materials at the high potential for a total of $130 \mathrm{~h}$, as shown in Figure S3(a-f) (supplementary information) at a scan rate of $5 \mathrm{mV} / \mathrm{s}$.

The study carried out GCD at different specific current to examine the specific capacitance performance of the materials with the two-electrode system configuration. The GCD curves exhibited almost symmetrical triangular V-shapes indicating a typical character for good EDLC properties, as shown in Fig. 8. This shows a no Faradaic process in the materials, which usually leads to poor stability performance. The GCD features correspond very well with the CV performance in Fig. 7. There was consistency in the charge-discharge character for the three-electrode system (Fig. 6b) and the two-electrode configuration. The electrochemical (EC) evaluation for specific capacitance was estimated by Eq. (2) for ANN6, ANN7, and ANN8 materials, considering the mass loading of the two electrodes as total mass $[3,4]$. There was a variation in the calculated specific capacitance values of the devices, as shown in Figure S4a (supplementary information) with the applied current densities. The ANN7 sample material exhibited a maximum specific capacitance of $358.7 \mathrm{~F} / \mathrm{g}$ at $0.5 \mathrm{~A} / \mathrm{g}$. The specific capacitance of the assembled devices decreased with the increasing current densities for all sample materials (Figure S4a supplementary information). This is mainly due to limited electrolyte ion transfer and limited interaction at the electrode interface at higher current density [35]. The ANN8 exhibited a maximum specific capacitance of $347.8 \mathrm{~F} / \mathrm{g}$ at $0.5 \mathrm{~A} / \mathrm{g}$ current density. Also, ANN6 presented its highest specific capacitance of $241.3 \mathrm{~F} / \mathrm{g} 0.25 \mathrm{~A} / \mathrm{g}$ current density.

The energy density and the power density of the assembled devices were calculated according to equations (3) and (4), respectively, as presented in the Ragone plot shown in Figure S4b (supplementary information) for all the sample materials. The device assembled from ANN7 gave the highest energy density of $12.45 \mathrm{Wh} / \mathrm{kg}$ for a current density of $0.5 \mathrm{~A} / \mathrm{g}$ with a corresponding power density of $250 \mathrm{~W} / \mathrm{kg}$. This result is comparable and even higher than the symmetric assembled EDLC SCs reported in the literature $[4,5,8,9]$. The ANN6 sample material exhibited an energy density of $8.38 \mathrm{Wh} / \mathrm{kg}$ for a power density of $125 \mathrm{~W} / \mathrm{kg}$ at a current density of $0.25 \mathrm{~A} / \mathrm{g}$. The ANN8 sample material also presented an energy density of $12.08 \mathrm{Wh} / \mathrm{kg}$ with a corresponding power density of $250 \mathrm{~W} / \mathrm{kg}$ at $0.5 \mathrm{~A} / \mathrm{g}$ current density. The energy density is approximately the same as that of the ANN7 sample, which can further be tested for commercial applications of different supercapacitors.

The electrochemical impedance spectroscopy (EIS) was performed on all sample materials to determine the resistive behaviour of the electrode materials for supercapacitor application. The EIS was determined in the frequency range from $10 \mathrm{kHz}$ to $10 \mathrm{mHz}$ at $10 \mathrm{mV}$. The Nyquist plot of the sample materials are shown in Fig. 9 with the zoomed at high frequency in the insert and Figure S5 (Supplementary information) to expose the semicircle. The small semicircles at the real axis indicate low charge transfer resistance $\left(R_{C T}\right)$ at the sample interface, leading to high electrochemical performance [3]. The ANN7 sample material shown an $\mathrm{R}_{\mathrm{CT}}$ of $2.5 \Omega$ as the highest resistance, with ANN6 and ANN8 exhibiting an $\mathrm{R}_{\mathrm{CT}}$ 
of 1.1 and $1.3 \Omega$, respectively. The vertical behaviour at low frequency with the imaginary axis indicates low ion diffusion into the pores of the electrode materials shown in Fig. 9. This suggests high cycling stability and the ideal capacitive performance of the materials. The sample materials were also tested at $20 \mathrm{mV}$ to check the behaviour of the plots at higher potential, as shown in Figure S5. This suggested a similar behaviour at high frequency with a slight variation at a lower frequency. This indicates that at higher potential, there is little ion diffusion into the sample pores.

The study evaluated the stability test of the as-prepared devices using the voltage holding / floating method. The three sample materials exhibited almost no degradation for the electrochemical performance of the devices showing uniform behaviour, as shown in Figure S7 (Supplementary Information). The stability was carried out by holding the assembled device at a maximum potential of $1.0 \mathrm{~V}$ for $10 \mathrm{~h}$ after every three charge-discharge cycles repeated for $130 \mathrm{~h}$ at $0.5 \mathrm{~A} / \mathrm{g}$. The capacitance of the assembled devices remained almost constant throughout $130 \mathrm{~h}$ with no primary decrease with increased time and cycling. This indicates uniform wettability throughout the electrode/electrolyte ion interaction, and there were no trapped ions in the pores of the large porosity of the as-prepared electrode material [2]. The SCs showed excellent stability with $99 \%$ retention of the initial specific capacitance value even after $130 \mathrm{~h}$ holding. This superb stability of the assembled devices is attributed to the microporous nature of the prepared sample material that keeps the uniform wettability and easy access to electrolytic ion movement. The self-discharge test was carried out on the assembled devices after voltage holding to determine the life span. In the test, the device was charged fully to a maximum potential of $1.0 \mathrm{~V}$ at 0.5 $\mathrm{A} / \mathrm{g}$, then hold for $5 \mathrm{~min}$ before undergoing a self-discharge in an open circuit. Figure S8 (Supplementary information) exhibited an immediate drop for ANN6 sample material and lost 70\% of the potential within 20 min. ANN7 and ANN8 showed a linear drop of potential losing 70\% approximately after $4 \mathrm{~h}$ and $3 \mathrm{~h}$. The possible reduction may be due to the decomposition of water used in the electrolyte at higher potential since ionic strength depends on the electrolyte. The water splitting requires a minimum potential difference of approximately $1.23 \mathrm{~V}$.

\section{Conclusion}

The study successfully optimized the Zea mays (maize) cobs derived porous carbon (ANN) at different temperatures using $\mathrm{KOH}$ as the activation agent with a ratio of 1:4 under the nitrogen atmosphere. The activated porous carbon exhibited a remarkable increase in specific surface area, high porosity at increasing temperatures. The sample materials showed optimum surface functional groups of oxygen base and resulted in excellent electrochemical performance and stability for the supercapacitor application. The samples exhibited $99 \%$ stability for more than $130 \mathrm{~h}$ of repeated maximum voltage holding. The symmetric assembled device of ANN7 with $5 \mathrm{M} \mathrm{KOH}$ electrolyte in a two-electrode configuration system shown a maximum specific capacitance of $358.7 \mathrm{~F} / \mathrm{g}$ with an energy density of $12.45 \mathrm{Wh} / \mathrm{kg}$ at $0.5 \mathrm{~A} / \mathrm{g}$ and capacitance retention of $99 \%$ for $130 \mathrm{~h}$ of repeated voltage floating. This research showed that an increase in temperature of Activation of activated carbon from biomass has a notable improvement in the electrochemical performance of supercapacitors. Also, the activated carbon 
from Zea mays cobs with an appropriate activation agent can give better-performing electrode materials for various supercapacitor applications using $700^{\circ} \mathrm{C}$ as optimum temperature.

\section{Methods}

\section{Materials}

The Zea mays (maize) cobs were obtained from the nearby farms of the African University of Science and Technology (AUST) Abuja. The potassium hydroxide used (90\% SDFCL), hydrochloric acid, carbon black, PVDF, and NMP (99\% Sigma-Aldrich) were used.

The aim of this research study was to improve on the activation method for Activation of the biomass and also to up-cycling of agricultural biomass into carbon-based porous materials for supercapacitor electrode application. The work followed the design which includes; carbonization, grinding of carbonized samples with $\mathrm{KOH}$ as agent then keeping the materials for 3 hours in a desiccator before Activation. Activation was carried out under nitrogen atmosphere. The materials were characterised for the physicalchemical properties and energy storage application using EDLC.

\section{Preparation of activated carbon}

The cobs were cleaned and sized to approximately $\sim 3 \mathrm{~cm}^{3}$. The sample was dried in an oven at $110^{\circ} \mathrm{C}$ for $48 \mathrm{~h}$, then grounded and sieved to fraction using a $1.0 \mathrm{~mm}$ sieve. The cobs sample powder was synthesized using two steps at elevated temperatures. First, carbonization of raw material from the Zea mays at $400{ }^{\circ} \mathrm{C}$ for 90 minutes with a $3{ }^{\circ} \mathrm{C} / \mathrm{min}$ ramp under the nitrogen atmosphere. These portions were grinded with $\mathrm{KOH}$ in a mass ratio of 1:3, then kept in the desiccator for 3 hours to allow intercalation of the carbon lattice expansion by $\mathrm{K}^{+}$ion. The Activation carried out in a furnace under a nitrogen atmosphere with a flow rate of $300 \mathrm{~mL} / \mathrm{min}$ with a ramped temperature of $3^{\circ} \mathrm{C} / \mathrm{min}$ and a holding time of $2 \mathrm{~h}$. The first (1st) portion was activated at $600^{\circ} \mathrm{C}$, and the sample was named ANN6, the second (2nd) and the third (3rd ) portions were heated at $700{ }^{\circ} \mathrm{C}$, and $800^{\circ} \mathrm{C}$ then labelled ANN7 and ANN8, respectively. The samples were washed with $0.1 \mathrm{M} \mathrm{HCl}$ to removal all the $\mathrm{K}+$ ions and making them neutral. $[1,36]$.

\section{Material Characterization}

The morphological and elemental composition of the samples were examined by a Field Emission Scanning Electron Microscope ((FESEM) Gemini-SEM 500M/s Carl ZEISS-EDAX Z2 Analyser AMETEK) Bangalore, India. X-Ray Diffraction (XRD) patterns were obtained by Rigaku Smart lab Autosampler XRD scanned from 8 to $100 \mathrm{deg}$ (RIGAKU Corp., Tokyo, Japan) equipped with a Cu ka radiation (wavelength $\lambda$ $=1.54 \AA$ ) and the JCPDS-ICDD database [37]. The samples' thermogravimetric analysis (TGA) was executed using a TGA-DSC analyzer (Jupiter STA449 F3 NTZSCH GmbH) Selb, Germany. The samples were heated in pure air at a flow rate of $10 \mathrm{~cm}^{3} / \mathrm{min}$ from room temperature to $1000{ }^{\circ} \mathrm{C}$ at a ramped temperature of $10^{\circ} \mathrm{C} / \mathrm{min}$ with a run time of 100 min using a calcinated silica pan reference material [38- 
40]. The surface chemistry and functional groups of $A C$ samples were examined by Fourier

Transformation InfraRed (FTIR) spectroscopy (Bruker Optik GmbH Vertex 70, Ettlingen, Germany) scanned from 600 to $4000 \mathrm{~cm}^{-1}$. The X-ray Photoelectron Spectroscopy (XPS) method with spectra in the K-alpha Photoelectron spectrometer using omicron Nano Technology London, UK. [41, 42]. The Nitrogen adsorption and desorption isotherms of the activated samples were obtained using a 77K automated adsorption instrument (11-2370. Gemini Miceomeritics, Atlanta, GA, USA). The AC samples were degassed at $300^{\circ} \mathrm{C}$ in a vacuum for $10 \mathrm{~h} \mathrm{[1].}$

\section{Electrochemical characterization}

The two and three-electrode systems configuration measurements were employed using BIO-LOGIC (BCS805) workstation operating on the BT-Lab software. The working electrodes were prepared by mixing the active materials $80 \%$, carbon black $10 \%$, and $10 \%$ binder (poly Vinylidene). In the mixture, a few drops of 1-methyl-2-pyrrolidine (NMP) were added to form a uniform paste coated on a graphite foil as the current collector for the electrodes. The coated electrodes were dried in an electric oven at $70^{\circ} \mathrm{C}$ for $15 \mathrm{~h}$. The electrochemical measurements, including galvanostatic charge-discharge (GCD), cyclic voltammetry (CV), electrochemical impedance spectroscopy (EIS), stability, and self-discharge, were examined using a $6 \mathrm{M}$ $\mathrm{KOH}$ aqueous electrolyte. The three-electrode configuration system used the as-prepared materials as working electrodes, $\mathrm{Ag} / \mathrm{AgCl}$ as a reference electrode and Pt as the counter electrode. The CV and GCD were carried out using a potential range from 0 to $1.0 \mathrm{~V}$. The two-electrode measurement was carried out with two working electrodes with similar mass load separated by cellulose filter paper assembled in a Swagelok symmetrical setup with $6 \mathrm{M} \mathrm{KOH}$ aqueous solution, and the device left to stabilize for 2 hours to increase wettability. The study investigated by $\mathrm{CV}$ and GCD properties between 0 to $1.0 \mathrm{~V}$ potential, and the EIS test was performed in the frequency range of $10 \mathrm{kHz}$ to $10 \mathrm{mHz}$ at $10 \mathrm{mV}$. The study carried out the stability of the device with the floating technique (voltage holding) as described in [1, 42], and the selfdischarge was performed by charging the device to a maximum voltage the held for $5 \mathrm{~min}$ then left to self-discharge to determine the percentage voltage loss with time as described by [43-45].

The Specific capacitance $\left(\mathrm{c}_{\mathrm{sp}} \mathrm{F} / \mathrm{g}\right)$ with three-electrode were calculated using GCD Eq. $(1)$, $[3,4,8,13]$.

$C_{s p}=\frac{I \Delta t}{m \Delta V}$

Where; I is the discharge current (A), $\Delta t$ is the discharge time (s), $\Delta \mathbf{V}$ is the applied potential window $(\mathrm{V})$, and $\mathbf{m}$ is the coated mass of the active materials $(\mathrm{g})$. The specific capacitance of a single electrode in the two-electrode symmetric setup was calculated using Eq. (2) $[3,46]$.

$C=4 \frac{I \Delta t}{M \Delta V}$

Where; $\mathrm{C}$ is the capacitance $(\mathrm{F} / \mathrm{g}), \mathrm{l} / \mathrm{M}$ is the specific current $(\mathrm{A} / \mathrm{g}), \Delta \mathrm{t}$ is the discharge time $(\mathrm{s})$, and $\Delta \mathrm{V}$ is the potential window $(\mathrm{V})$. The energy density $(\mathrm{E}, \mathrm{Wh} / \mathrm{kg})$ and power density $(\mathrm{P}, \mathrm{W} / \mathrm{kg})$ of the symmetric device supercapacitor was calculated using the following equations 

$E=\frac{C(\Delta V)^{2}}{28.8}$
$P=3600 \frac{E}{\Delta t}$

\section{Abbreviations}

EDLC Electrochemical double layer capacitors

EC Electrochemical

SC Supercapacitors

CV Cyclic voltammetry

GCD Galvanostatic Charge-Discharge

EIS Electrochemical impendence spectrometry

IR Internal resistance

FTIR Fourier Transform Infrared Spectroscopy

PVDF Polyvinylidene fluoride

NMP 1-methyl-2-pyrrolidine

ANN Activated in nitrogen atmosphere

TGA Thermal gravimetric analysis

DSC Differential Scanning calorimetry

SEM-EDX Scanning electron microscopy - Energy Dispersive X-Ray Analysis

XRD X-ray powder diffraction

XPS X-Ray Photoelectron Spectroscopy

\section{Declarations}

Ethics approval and consent to participate

Not applicable

Consent for publication 
Not applicable

Availability of data and materials

All data generated or analysed during this study are included in this published article [and its supplementary information files].

Competing interests

The authors declare that they have no competing interests

Funding

This work was sponsored by the MAPRONANO ACE Makerere University project (P151847 / IDA 5797-UG) and supported by both the India- DST World Bank Cooperation on Strengthening of African Centres of Excellence (Grant No: DST/INT/AFRICA/ACEs/2016) and the African Development Bank and Pan African Materials Institute at the African University of Science and Technology (Grant No: PAMI/2015/5415-NG).

Authors' contributions

N Y D, A P O, PK J, JBK and GNK conceptuses, designed and supervised the experiments and ran the administrative work. MK, R K, BP, AB, R K K, KO, and OLM K performed synthesis and characterization studies and made the first draft. All the authors reviewed and agreed on this version of the manuscript.

Acknowledgements

This research work was conducted under the INDO-African knowledge transfer program under the World Bank Development program. The authors thank ARCI under DST India for supporting this study through the research fellowship scheme. MK acknowledges Dr P.K Jain from ARCl and Annet Nanyitti for support. NYD. Acknowledges the UK Engineering and Physical Sciences Research Council (EPSRC) funding (Grant No. EP/S001395/1).

\section{References}

1. Kigozi M, Kali R, Bello A, Padya B, Kalu-uka GM, Wasswa J, Jain PK, Onwualu PA, N. Y. Dzade. (2020)., Modified Activation Process for Supercapacitor Electrode Materials from African Maize Cob. Materials, Vol: 13, pp. 1-21; DOI:10.3390/ma13235412

2. Tarimo DJ, Oyedotun KO, Mirghni AA, Sylla NF, Manyala N. (2020)., High energy and excellent stability asymmetric supercapacitor derived from sulphur-reduced graphene oxide/manganese dioxide composite and activated carbon from peanut shell. Electrochimica Acta, Vol: 353, pp.

DOI:10.1016/j.electacta.2020.136498

3. Kigozi M, Koech RK, Kingsley O, Ojeaga I, Tebandeke E, Kasozi G, Onwualu PA. (2020)., Synthesis and characterization of graphene oxide from locally mined graphite flakes and its supercapacitor 
applications. Results in Materials, Vol: 100113, pp. DOl:10.1016/j.rinma.2020.100113

4. Rajesh M, Manikandan R, Kim BC, Park S, Cho W-J, Yu KH, Raj CJ. (2020)., Pinecone biomass-derived activated carbon: the potential electrode material for the development of symmetric and asymmetric supercapacitors. Energy Research, 1-15; DOI:10.1002/er.5548

5. Hsiao C, Lee C, Tai N. (2020)., Biomass-derived three-dimensional carbon framework for a flexible fibrous supercapacitor and its application as a wearable smart textile. RSC Advances, Vol: 10, pp. 6960-6972; DOI:10.1039/c9ra07441d

6. Wang J, Li Q, Peng C, Shu N, Niu L, Zhu Y. (2020)., To increase electrochemical performance of electrode material by attaching activated carbon particles on reduced graphene oxide sheets for supercapacitor. Journal of Power Sources, Vol: 450, pp. 227611;

DOI:10.1016/j.jpowsour.2019.227611

7. Muzaffar A, Ahamed MB, Deshmukh K, Thirumalai J. (2019)., A review on recent advances in hybrid supercapacitors: Design, fabrication and applications. Renewable and Sustainable Energy Reviews, Vol: 101, pp. 123-145; DOI:10.1016/j.rser.2018.10.026

8. Malothu RU, Nanaji K, Narasinga TR, Suresh AD. (2020)., Corn husk derived activated carbon with enhanced electrochemical performance for high-voltage supercapacitors. Journal of Power Sources, Vol: 471, pp. 228387; DOI:10.1016/j.jpowsour.2020.228387

9. Inal IIG, Aktas Z. (2020)., Applied Surface Science Enhancing the performance of activated carbon based scalable supercapacitors by heat treatment. Applied Surface Science, Vol: 514, pp. 145895; DOI:10.1016/j.apsusc.2020.145895

10. Xie X, Wu D, Wu H, Hou C, Sun X, Zhang Y, Yu R, Zhang S, ... Du W. (2020)., Dielectric parameters of activated carbon derived from rosewood and corncob. J Mater Scie: Mater Electron, 8; DOI:10.1007/s10854-020-04358-8

11. Nguyen TN, Le PA, Phung VBT. (2020)., Facile green synthesis of carbon quantum dots and biomassderived activated carbon from banana peels: synthesis and investigation. Biomass Conversion and Biorenery, pp. DOI:10.1007/s13399-020-00839-2

12. Lin Y, Chen Z, Yu C, Zhong W. (2020)., Electrochimica Acta Facile synthesis of high nitrogen-doped content, mesopore-dominated biomass-derived hierarchical porous graphitic carbon for high performance supercapacitors. Electrochem. Soc. 148 (2001) A149., Vol: 334, pp. 135615; DOI:10.1016/j.electacta.2020.135615

13. Liu M, Li W, Ruan S, Fei Y. (2020)., N - doped Hierarchical Mesoporous Carbon from Mesophase Pitch and Polypyrrole for Supercapacitors. Energy and Fuels, Vol: 34, pp. 5044-5052; DOI:10.1021/acs.energyfuels.0c00176

14. Inagaki M, Konno H, Tanaike O. (2010)., Carbon materials for electrochemical capacitors. Journal of Power Sources, Vol: 195, pp. 7880-7903; DOI:10.1016/j.jpowsour.2010.06.036

15. Centeno TA, Sevilla M, Fuertes AB, Stoeckli F. (2005)., On the electrical double-layer capacitance of mesoporous templated carbons. Carbon, Vol: 43, pp. 3012-3015 
16. Zhi M, Yang F, Meng F, Li M, Manivannan A, Wu N (2014) Effects of Pore Structure on Performance of An Activated-Carbon Supercapacitor Electrode Recycled from Scrap Waste Tire. ACS Sustainable Chemistry \& Engineering

17. Zhi M, Xiang C, Li J, Li M, Wu N. (2013)., Nanostructured carbon-metal oxide composite electrodes for supercapacitors: a review. Nanoscale, Vol: 5, pp. 72-88

18. Lu H, Zhao X. (2017)., Biomass-derived carbon electrode materials for supercapacitors. Sustainable Energy Fuels, Vol: 1, pp. 1265-1281; DOI:10.1039/C7SE00099E

19. Raj CJ, Rajesh M, Manikandan R, Yu KH, Anusha JR, Ahn JH, Kim DW, Park SY, Kim BC. (2018)., High electrochemical capacitor performance of oxygen and nitrogen enriched activated carbon derived from the pyrolysis and activation of squid gladius chitin. Journal of Power Sources, Vol: 386, pp. 6676; DOI:10.1016/j.jpowsour.2018.03.038

20. Wang CH, Wen WC, Hsu HC, Yao BY. (2016)., High-capacitance KOH-activated nitrogen-containing porous carbon material from waste coffee grounds in supercapacitor. Advanced Powder Technology, Vol: 27, pp. 1387-1395; DOI:10.1016/j.apt.2016.04.033

21. Yang J, Xiang F, Guo H, Wang L, Niu X. (2020)., Honeycomb-like porous carbon with N and S dualdoping as metal- free catalyst for the oxygen reduction reaction. Carbon, Vol: 156, pp. 514-522; DOI:10.1016/j.carbon.2019.09.087

22. Sudhan N, Subramani K, Karnan M, Ilayaraja N, Sathish M. (2017)., Biomass-derived activated porous carbon from rice straw for a high-energy symmetric supercapacitor in aqueous and nonaqueous electrolytes. Energy and Fuels, Vol: 31, pp. 977-985; DOI:10.1021/acs.energyfuels.6b01829

23. Qiu X, Wang L, Zhu H, Guan Y, Zhang Q. (2017)., Lightweight and efficient microwave absorbing materials based on walnut shell-derived nano-porous carbon. Nanoscale, Vol: 9, pp. 7408-7418; DOI:10.1039/c7nr02628e

24. Zequine C, Ranaweera CK, Wang Z, Singh S, Tripathi P, Srivastava ON, Gupta BK, Ramasamy K,... Gupta RK. (2016)., High per formance and flexible supercapacitors based on carbonized bamboo fibers for wide temperature applications. Scientific Reports, Vol: 6, pp. 1-10; DOI:10.1038/srep31704

25. Ji L, Wang B, Yu Y, Wang N, Zhao J, Wang B, Yu Y, Wang N, Zhao J. (2019)., N, S co-doped biomass derived carbon with sheet-like microstructures for supercapacitors. Electrochemica Acta, Vol: 19, pp. DOI:10.1016/j.electacta.2019.135348

26. Zhao H, Lu X, Wang Y, Sun B, Wu X, Lu H. (2017)., Effects of additives on sucrose-derived activated carbon microspheres synthesized by hydrothermal carbonization. Journal of Materials Science, Vol: 52, pp. 10787-10799; DOI:10.1007/s10853-017-1258-4

27. Chen W, Hu C, Yang Y, Cui J, Liu Y. (2016)., Rapid synthesis of carbon dots by hydrothermal treatment of lignin. Materials, Vol: 9, pp. DOI:10.3390/ma9030184

28. Liu B, Liu Y, Chen H, Yang M, Li H. (2017)., Oxygen and nitrogen co-doped porous carbon nanosheets derived from Perilla frutescens for high volumetric performance supercapacitors. Journal of Power Sources, Vol: 341, pp. 309-317; DOI:10.1016/j.jpowsour.2016.12.022 
29. Peng L, Liang Y, Dong H, Hu H, Zhao X, Cai Y, Xiao Y, Liu Y, Zheng M. (2018)., Super-hierarchical porous carbons derived from mixed biomass wastes by a stepwise removal strategy for highperformance supercapacitors. Journal of Power Sources, Vol: 377, pp. 151-160;

DOI:10.1016/j.jpowsour.2017.12.012

30. Chen Y, Jing C, Fu X, Shen M, Li K, Liu X, Yao C, Zhang Y, ... Yao KX (2019) Synthesis of porous NiCoS nanosheets with Al leaching on ordered mesoporous carbon for high-performance supercapacitors. Chemical Engineering Jounal. pp. DOI:10.1016/j.cej.2019.123367

31. Juan D, Zhang Y, Wu H, Hou S, Chen A. (2020)., N-doped hollow mesoporous carbon spheres by improved dissolution-capture for supercapacitors. Carbon, Vol: 156, pp. 523-528; DOI:10.1016/j.carbon.2019.09.091

32. Li R, Zhou Y, Li W, Zhu J, Huang W. (2020)., Structure Engineering in Biomass-Derived Carbon Materials for Electrochemical Energy Storage. Research AAAS, Vol: 2020, pp. 27; DOI:10.34133/2020/8685436

33. Lokhande PE, Chavan US, Pandey A. (2019)., Materials and Fabrication Methods for Electrochemical Supercapacitors: Overview

34. Liu J, Deng Y, Li X, Wang L. (2016)., Promising Nitrogen-Rich Porous Carbons Derived from One-Step Calcium Chloride Activation of Biomass-Based Waste for High Performance Supercapacitors. ACS Sustainable Chemistry and Engineering, Vol: 4, pp. 177-187; DOI:10.1021/acssuschemeng.5b00926

35. Raj CJ, Rajesh M, Manikandan R, Sim JY, Yu KH, Park SY, Song JH, Kim BC. (2017)., TwoDimensional Planar Supercapacitor Based on Zinc Oxide/Manganese Oxide Core/Shell Nanoarchitecture. Electrochimica Acta, Vol: 247, pp. 949-957; DOI:10.1016/j.electacta.2017.07.009

36. Reece R, Lekakou C, Smith PA. (2018)., A structural supercapacitor based on activated carbon fabric and a solid electrolyte. TF Materials Science and Technology, Vol: 35, pp. 368-375;

DOI:10.1080/02670836.2018.1560536

37. Kigozi M, Ezealigo BN, Onwualu AP, Dzade NY. (2021)., "Hydrothermal synthesis of metal oxide composite cathode materials for high energy application." Chem. Depos. Nanocrystalline Met. Oxide Thin Film., 489

38. Lim WC, Srinivasakannan C, Balasubramanian N. (2010)., Activation of palm shells by phosphoric acid impregnation for high yielding activated carbon. Journal of Analytical and Applied Pyrolysis, Vol: 88, pp. 181-186; DOI:10.1016/j.jap.2010.04.004

39. Van K, Le T, Thuy L, Thi. (2014)., Activated carbon derived from rice husk by NaOH activation and its application in supercapacitor. Progress in Natural Science: Materials International, Vol: 24, pp. 191198; DOI:10.1016/j.pnsc.2014.05.012

40. Lijuan H, Peng Y, Feng W, Peng S, JinJun L, Zizheng L. (2017)., Tubular activated carbons made from cotton stalk for dynamic adsorption of airborne toluene. Journal of The Taiwan Institute of Chemical Engineers, Vol: 80, pp. 399-405; DOI:10.1016/j.jtice.2017.07.029

41. Shafeeyan MS, Wan MWA, Houshmand A, Shamiri A. (2010)., A review on surface modification of activated carbon for carbon dioxide adsorption. Journal of Analytical and Applied Pyrolysis, Vol: 89, 
pp. 143-151; DOI:10.1016/j.jaap.2010.07.006

42. Elmouwahidi A, Esther B-G, Agustin FP-C, Francisco JM-H, Francisco C-M. (2017)., Activated carbons from $\mathrm{KOH}$ and $\mathrm{H} 3 \mathrm{PO} 4$-activation of olive residues and its application as supercapacitor electrodes. Electrochimica Acta, Vol: 229, pp. 219-228; DOI:10.1016/j.electacta.2017.01.152

43. Barzegar F, Khaleed AA, Ugbo FU, Oyeniran KO, Momodu DY, Bello A, Dangbegnon JK, Manyala N. (2016)., Cycling and floating performance of symmetric supercapacitor derived from coconut shell biomass. AIP Advanced, Vol: 6, pp. 9; DOI:10.1063/1.4967348

44. Moyo B, Momodu D, Fasakin O, Dangbegnon J, Manyala N. (2018)., materials Electrochemical analysis of nanoporous carbons derived from activation of polypyrrole for stable supercapacitors. Energy Materials, Vol: 53, pp. 5229-5241; DOI:10.1007/s10853-017-1911-y

45. Bello A., F. Barzegar, M. J. Madito, D. Y. Momodu, A. A. Khaleed, O. Olaniyan, T. M. Masikhwa, Masikhwa, ... N. Manyala. (2017)., Floating of PPY Derived Carbon Based Symmetric Supercapacitor in Alkaline Electrolyte. E C S Society, The Electrochemical, Vol: 75, pp. 1-12;

DOI:10.1149/07524.0001ecst.

46. Wei H., H. Wang, A. Li, H. Li, D. Cui, M. Dong, J. Lin, J. Fan, ... Z. Guo. (2019)., Advanced porous hierarchical activated carbon derived from agricultural wastes toward high performance supercapacitors. Alloys and Compounds, pp. DOI:10.1016/j.jallcom.2019.153111.

\section{Figures}



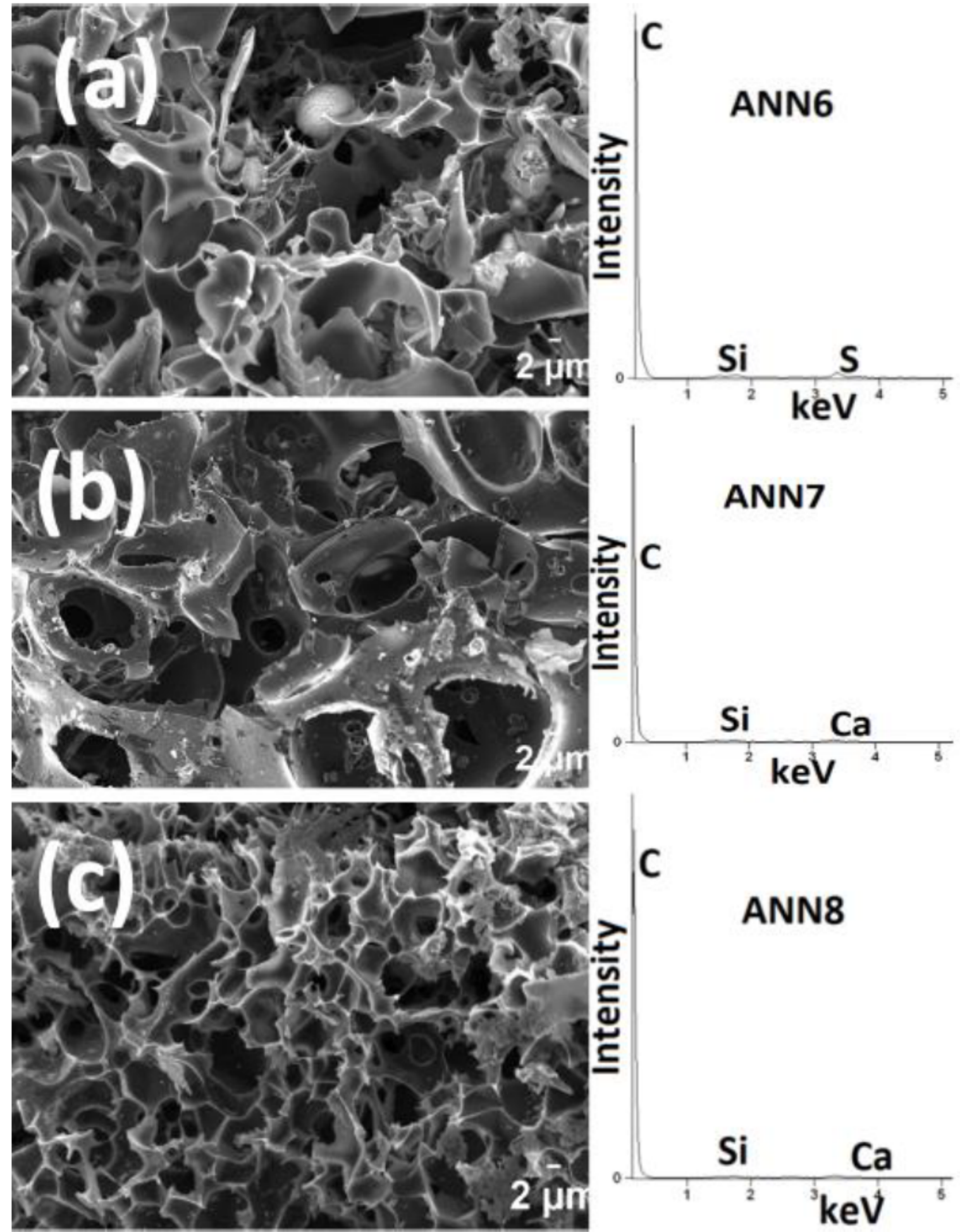

Figure 1

FESEM/EDX morphology and compositions for (a) ANN6, (b) ANN7, and (c) ANN8 samples 
(a)

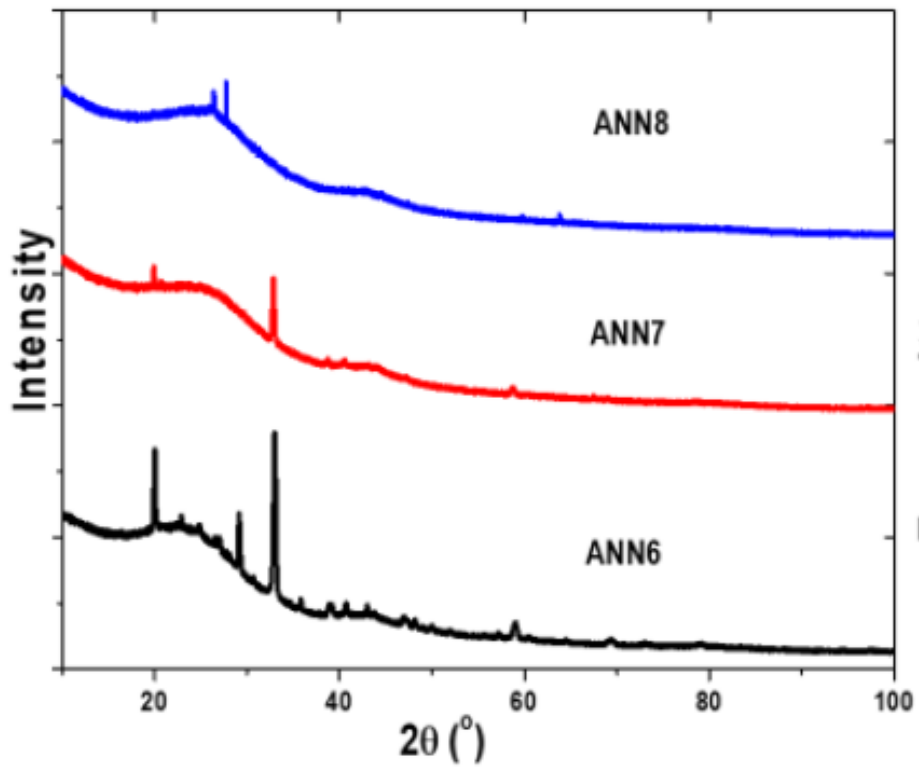

(b)

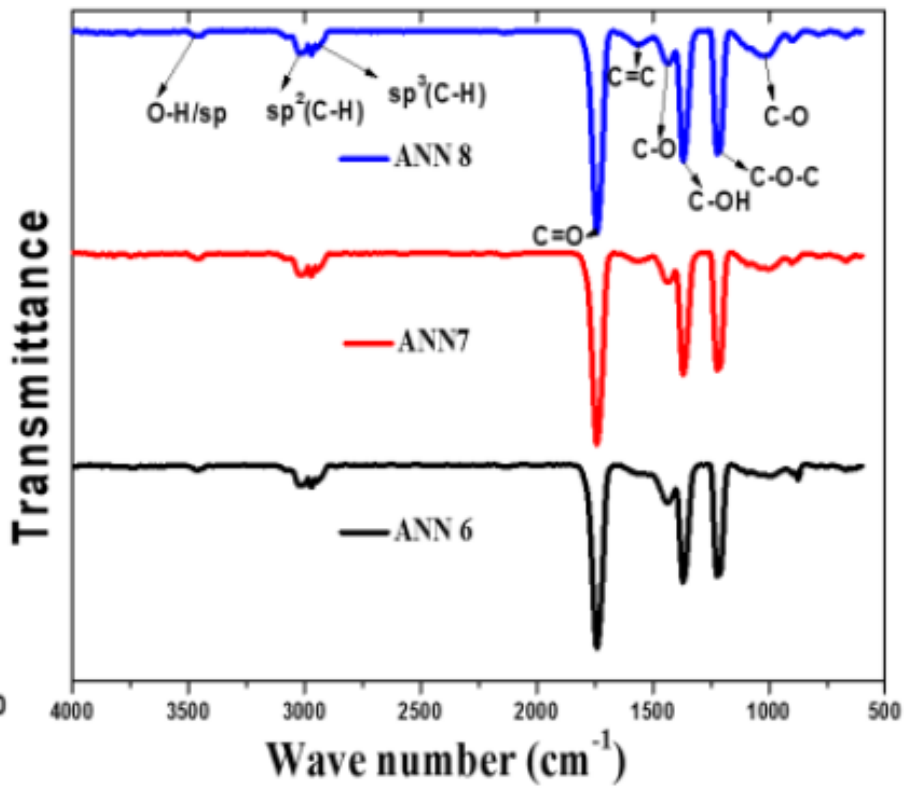

Figure 2

(a) XRD spectra, (b) FTIR spectra for ANN6, ANN7, and ANN8 activated carbon. 


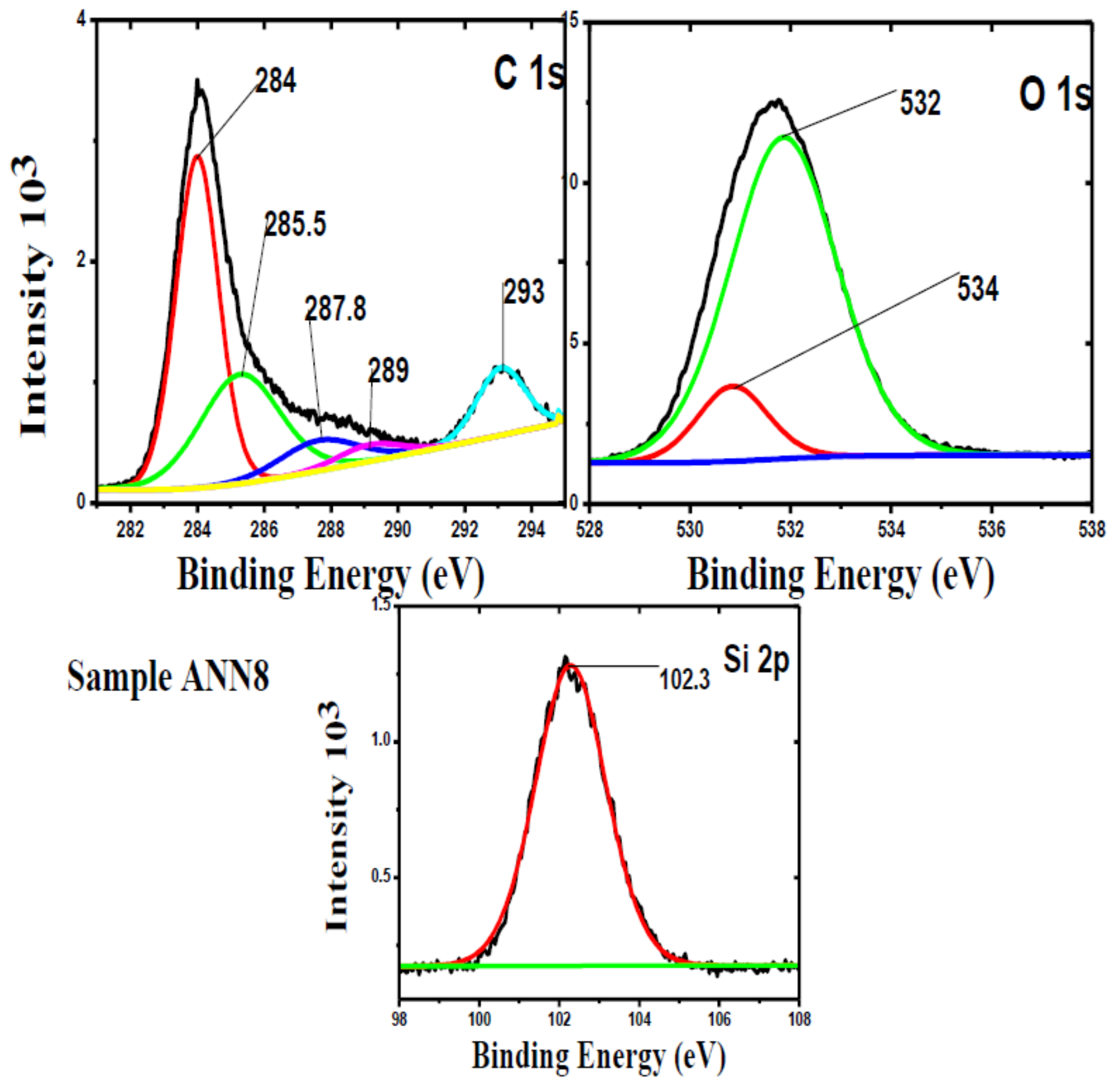

Figure 3

XPS deconvoluted spectra for ANN8 activated sample 
(a)

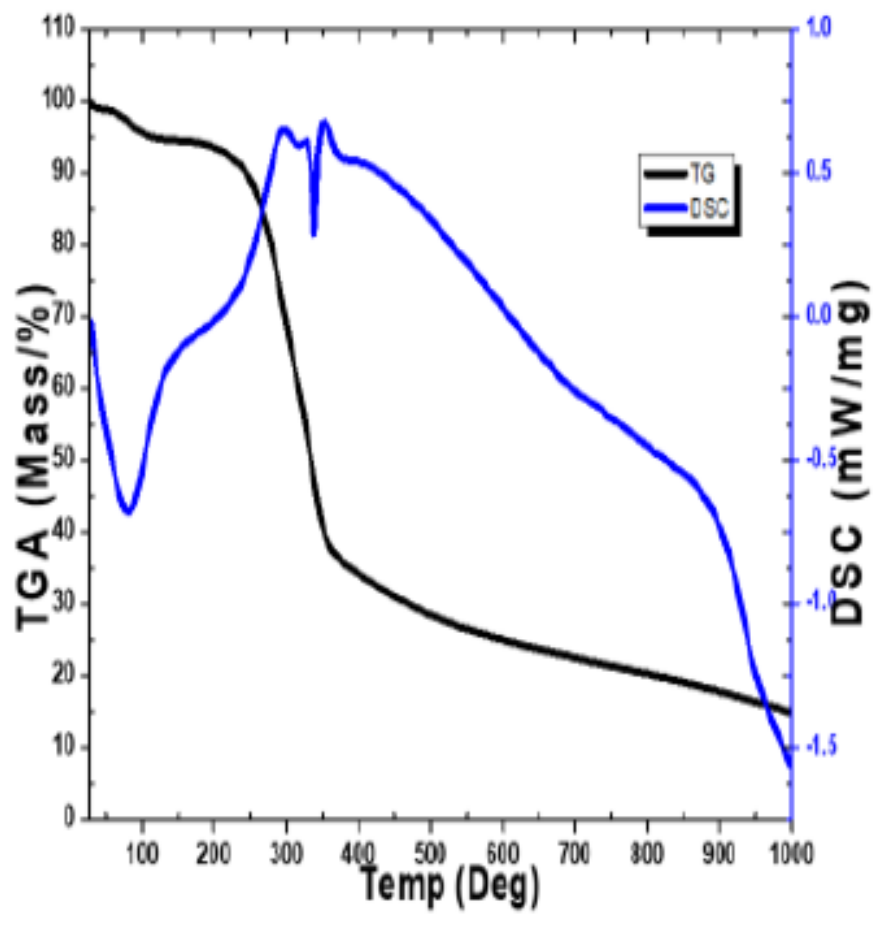

(b)

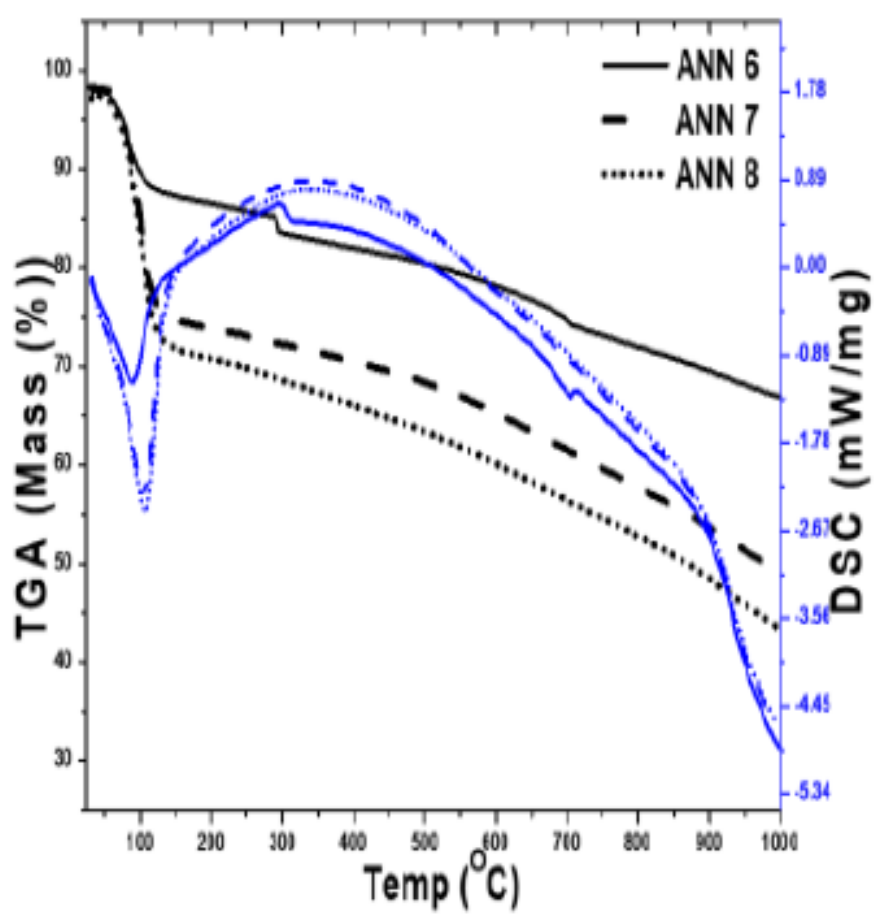

Figure 4

TGA/DSC profile (a) Zea mays cobs and (b) activated carbon ANN6, ANN7, and ANN8.

(a)

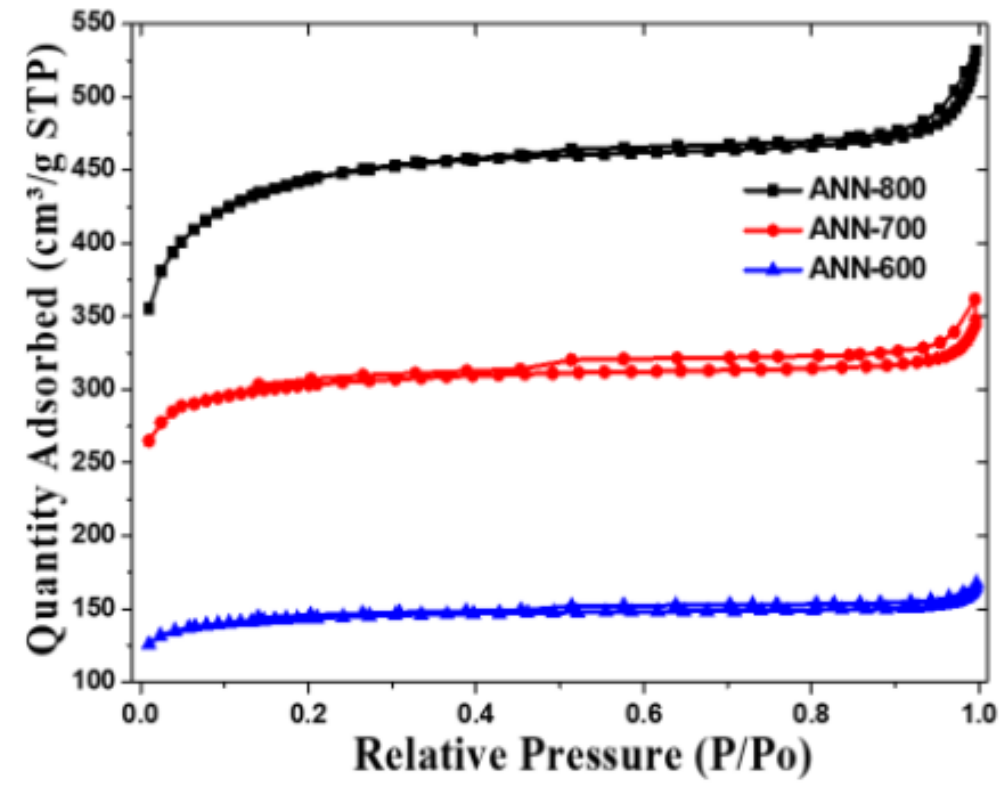

(b)

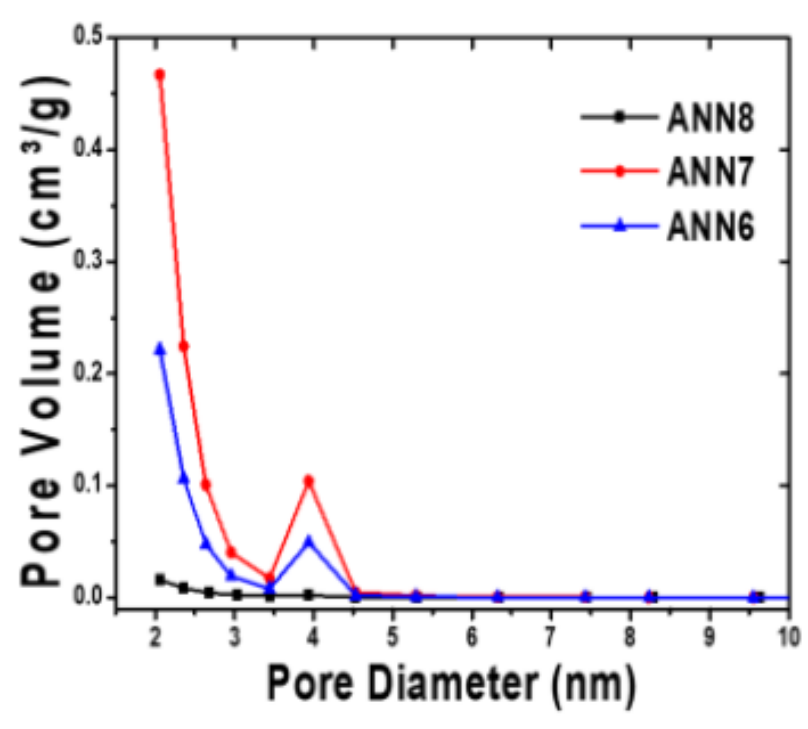

Figure 5 
(a) N2 adsorption-desorption isotherms and (b) Pore size distribution of the activated carbon samples.

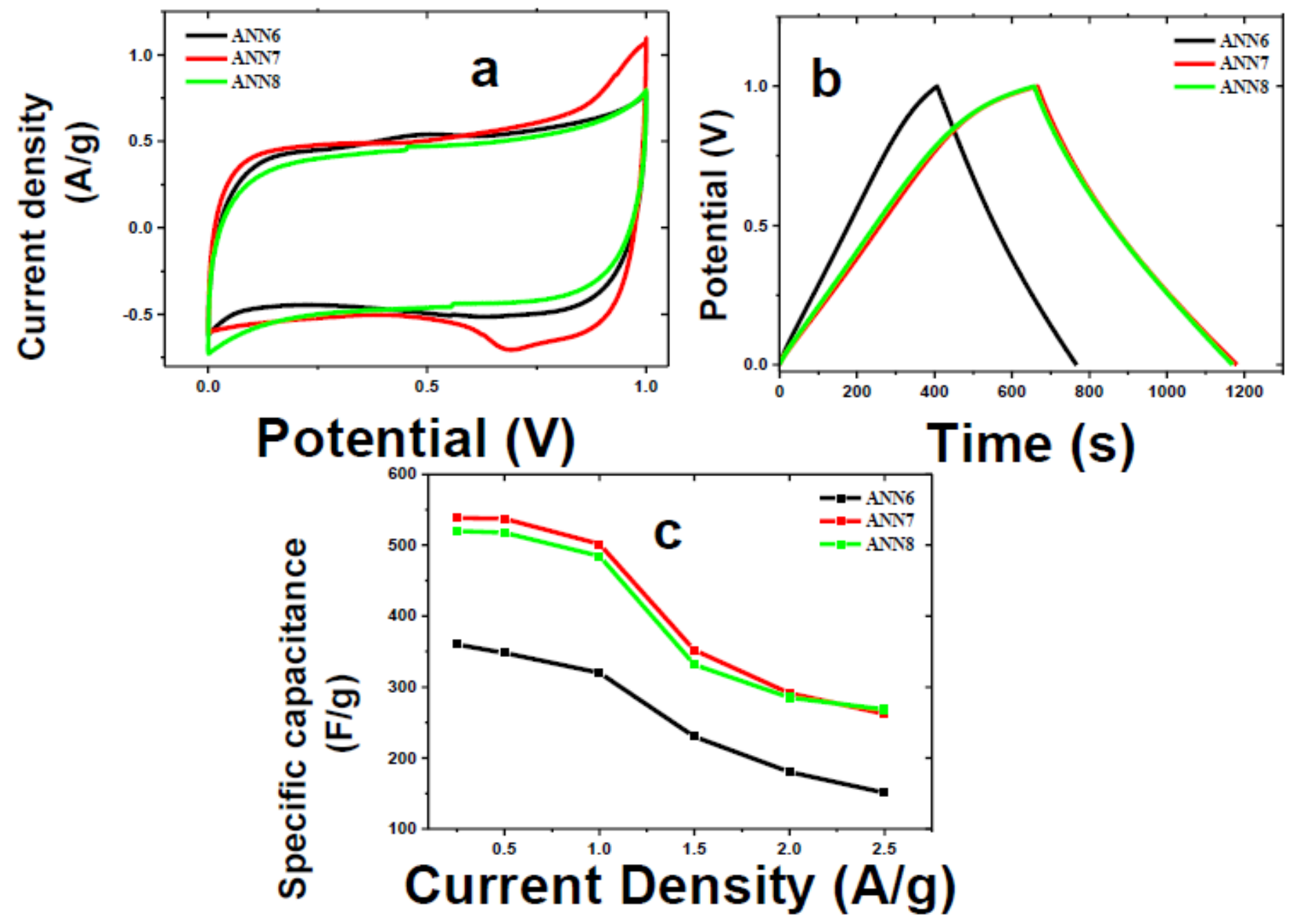

Figure 6

(a) CVs at a scan rate of $10 \mathrm{mV} / \mathrm{s}$, (b) GCD carried at a current density of $0.25 \mathrm{~A} / \mathrm{g}$, (c) specific capacitance with different current densities of ANN6, ANN7, and ANN8 activated carbon samples. 

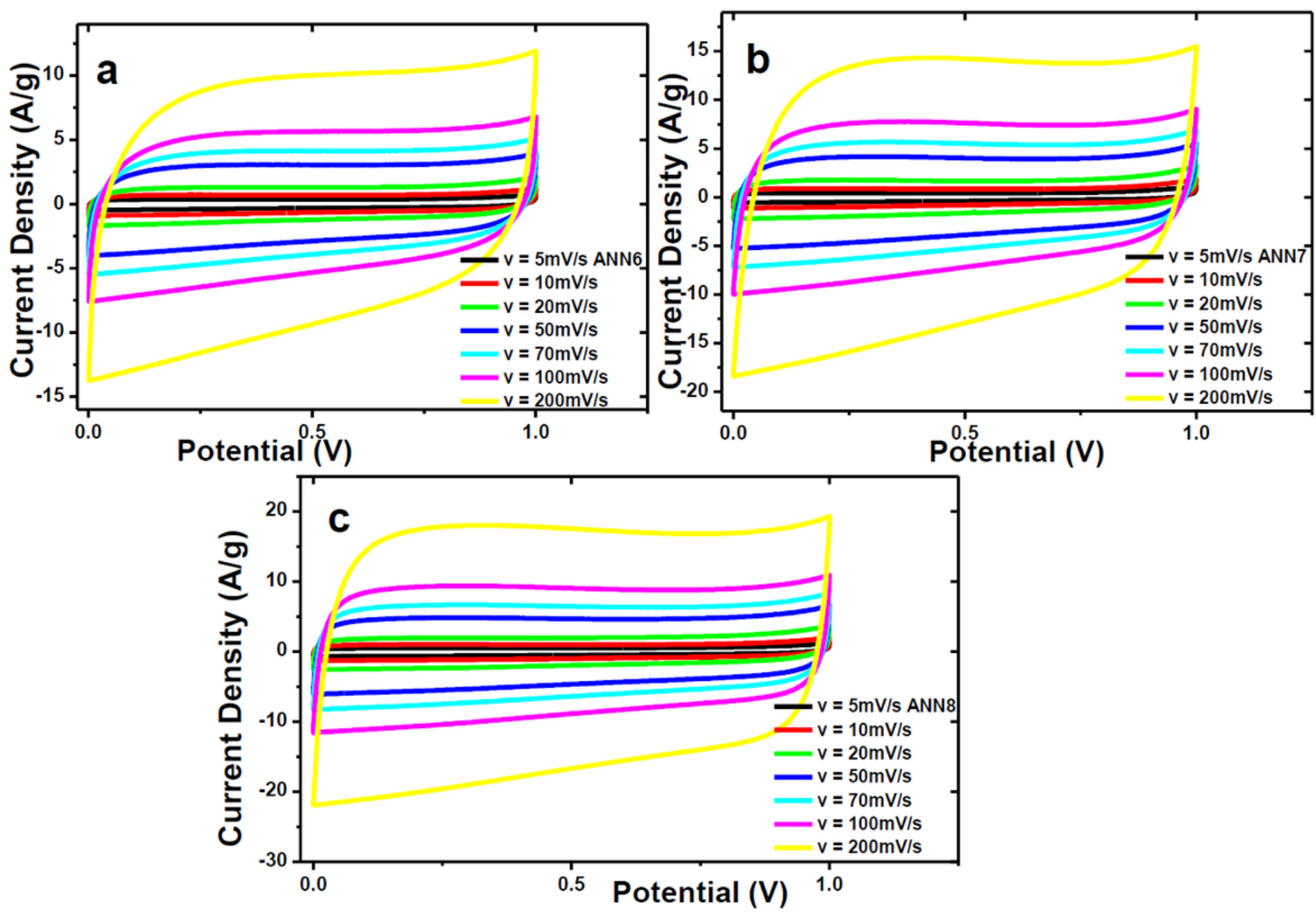

Figure 7

CV curves for (a) ANN6, (b) ANN7, and (c) ANN8 carbon samples at different scan rates 

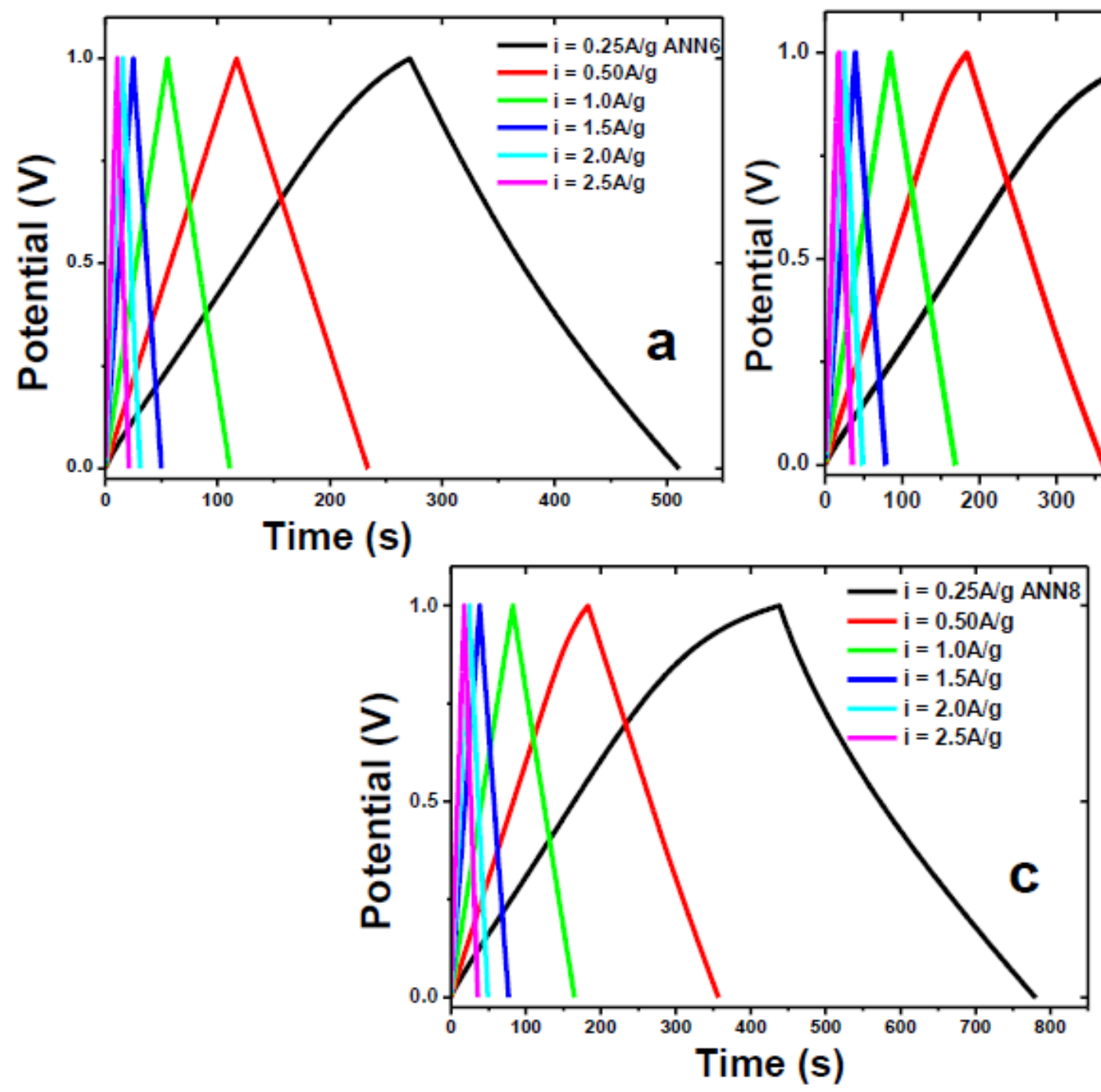

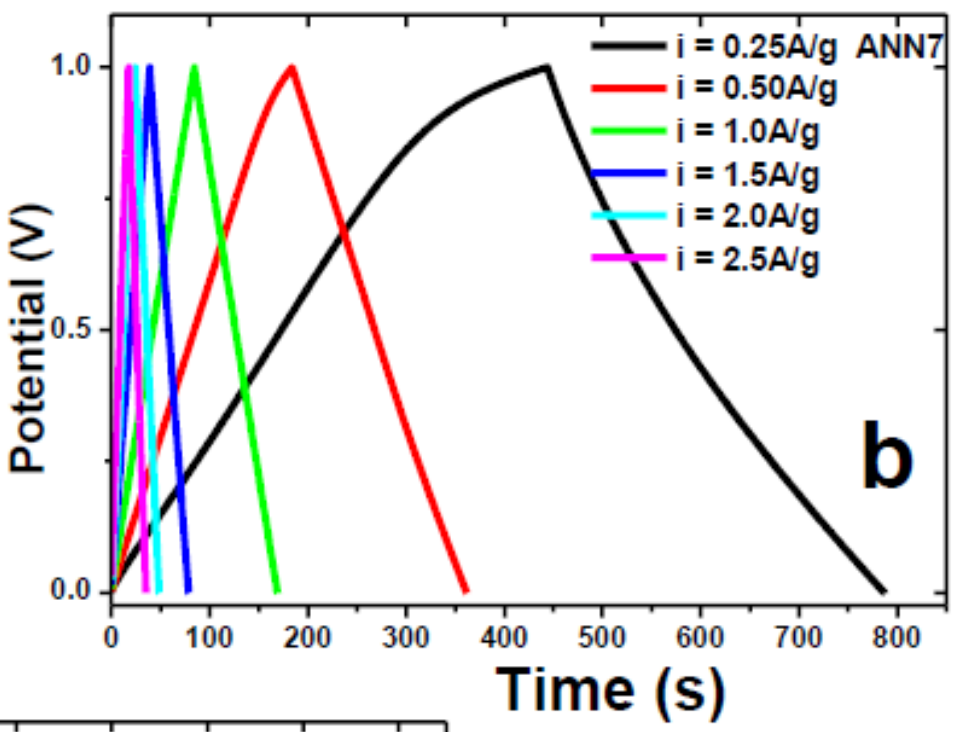

Time (s)

Figure 8

GCD curves for (a) ANN6, (b) ANN7, and (c) ANN8 carbon samples at different current densities. 


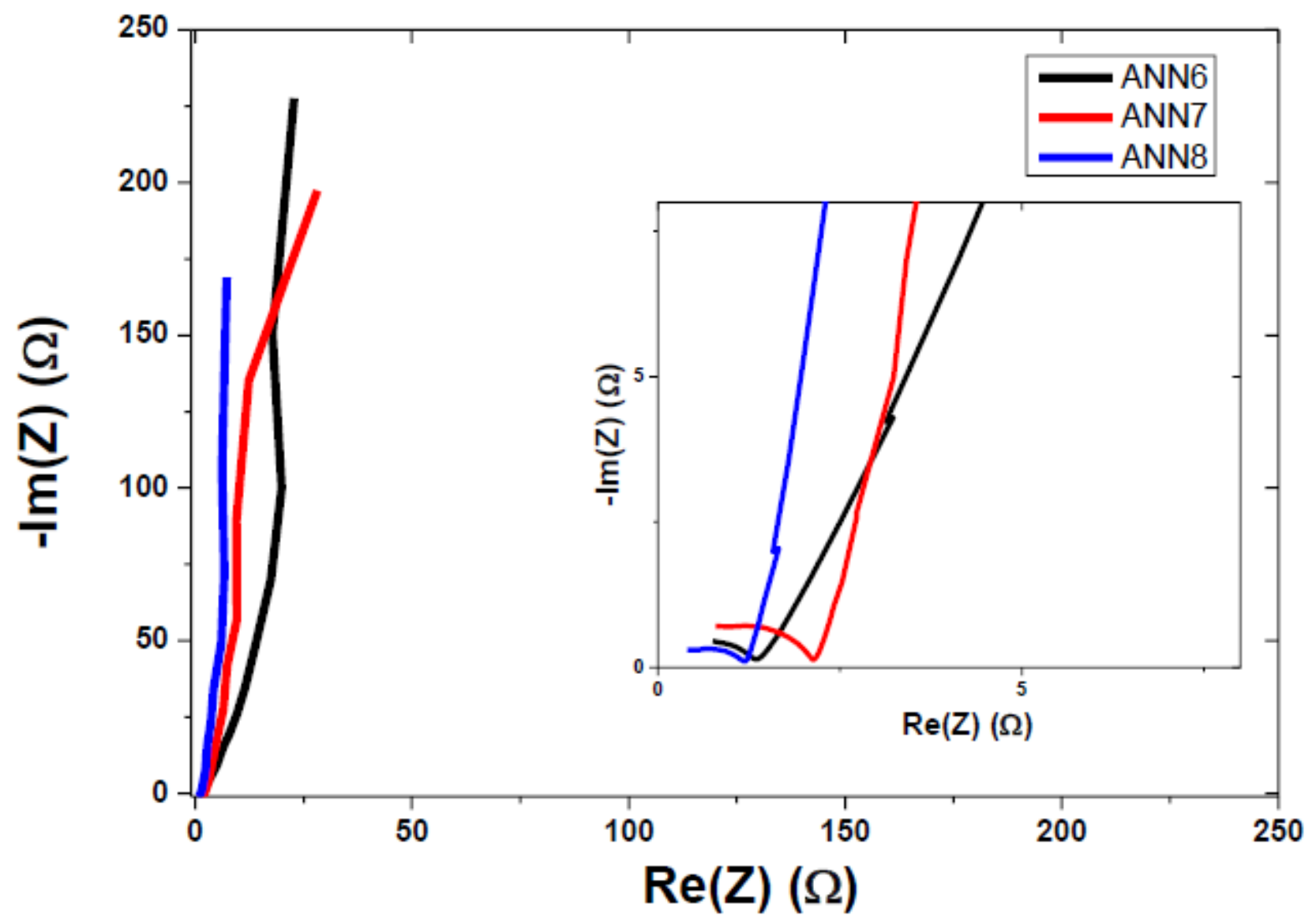

Figure 9

Figure EIS for ANN6, ANN7, and ANN8 activated carbon scanned at $10 \mathrm{mV}$, Insert is the zoomed high frequency.

\section{Supplementary Files}

This is a list of supplementary files associated with this preprint. Click to download.

- Supplimentaryinformation.docx 